\title{
Development of Ontology for the Representation of Adverse Drug Events of Diabetes Disease
}

\author{
NAKHLA Zina \\ BESTMOD Laboratory, High Institute \\ of Management, University of Tunis, \\ 41. City Bouchoucha, 2000 Bardo, \\ Tunis, Tunisia
}

\author{
NOUIRA Kaouther \\ BESTMOD Laboratory, High Institute \\ of Management, University of Tunis, \\ 41, City Bouchoucha, 2000 Bardo, \\ Tunis, Tunisia
}

\begin{abstract}
One of the main problems arising in the field of the health is the Adverse Drug Event (ADE). The computer system which aimed to prevent the ADE lacks the ADE knowledge standardization. So the background ADE knowledge is needed. This study presents ADE ontology of diabetes disease which includes the terms relative to the diabetes ADE. Our goal is to organize and structure the information relative to this type of problem, to facilitate the extraction of information used in the computer systems of detect and prevent the ADE specific for diabetes disease.
\end{abstract}

\section{General Terms}

Construction of Diabetes ADE Ontology .

\section{Keywords}

Ontology, Adverse Drug Event, Diabetes

\section{INTRODUCTION}

The mission of the health establishment is to assure the quality of care and patient safety. According to the American report of the Institute of medicine in 1999 [12], the medical error in the USA is considered as one of the major causes of death, the number of deaths caused by medical errors is between 44000 and 98000 per year [12]. One of the important medical errors is the Adverse Drug Events (ADE). The ADE is a not wanted harmful medicine reaction, it happens to patients during a taking of medicine with recommended dose in a preventive, diagnostic or therapeutic purpose [9]. It is an event which engenders problems of health for patients like temporary incapacities. Every ADE prolongates the duration of hospitalization to 2.2 days[9], we can even note deaths. The diabetes is one of the diseases which is sensitive to ADEs, because it affects many organs and causes many health problems. So the diabetic patient takes many type of drugs. Therefore the intense treatment of diabetes may become a heavy burden, which is susceptible of an ADE. For exemple a dangerous drug combination. Also diabetes is the leading cause of other diseases like blindness, renal failure, neuropathy, peripherial vascular disease... It has become an epidemic, that affects an important number of people. According to a National Report of the Tunisian public health Ministry in 2005 , the national total prevalence of diabetes is $8.4 \%$ for men and $8.7 \%$ for women. Diabetes is not only common and serious disease, it is also a very costly disease. According to the American Diabetes Association, the annual cost of diabetes in USA medical expenses rose from $\$ 132$ billion in 2002 to $\$ 174$ billion in 2007 [3]. In Tunisia
[1], the annual diabetes disease cost is 239TND per person per year in absence of complication, 1401 TND in presene of moderate complication and grows to 24725TND in case of severe complication. It is necessary to prevent the ADEs relative to diabetes disease to reduce and limit the effects of the dangerous acts put in the health system, spare patients from other health problems, improve the care quality and decrease the unnecessary health cost. The systems, which were developed in the literature to reduce the medical errors, have deficiencies which make them not optimal because the health domain composed on an important volume of information. The medical data regroup the information relative to patients, therapy, drugs, surgical operations, administration...etc. This information is collected from heterogeneous data sources, which can cause data process problems when we need to prevent medical errors. The absence of a high-level data structuralization, which allows to classify and to organize the knowledge, causes a problem of data extraction and analysis.

In this work, we propose ontology of diabetes ADE. This ontology aimes to organize and structure the disease information. It is a formal terms and concepts representation, defined in a given language and described the logical relationships between them. This ontology serves to understand the ADE domain and allows us to develep a preventive ADE system. Such system will be able to increase the health quality in the first hand, and decrease the unnecessary expenses, in the second hand.

This paper is structured as follows: the second section presents the state of art treating the ADE and the medical errors relative ontology. The third section presents the ADE ontology. The fourth section illustrates the construction of our diabetes's ADE ontology. Finally we will conclude and present our work perspectives.

\section{RELATED WORK}

To insure the patients safety, a common language is necessary between the various health services. For this goal a multiple medical ontologies are created. The International Classification Disease (ICD) [22] was used to classify diseases, conditions, a wide variety of signs, symptoms, and external causes of injuries or diseases. The ICD is published by the World Health Organization (WHO), The version-10 of ICD was created in 1992. It is used worldwide for morbidity and mortality statistics, reimbursement systems, and automated decision support in 
medicine [14]. The Internationational Classification of Primary Care (ICPC) [20] is a classification which aimed to classify the medical concepts in categories according to their relevance in the primary health care. The version of ICPC, which include criteria and definitions, was created in 1998. The Systematized Nomenclature of Medicine (SNOMED) [16] was created in 2002. It is a multiaxial, hierarchical classification system, it is an ontology of the healthcare aiming to make the knowledge in the medical domain accessible by all the medical community.

These different ontologies are treating medical problems in general, and they are not focusing in medical errors or ADEs. So this kind of ontologies can not be used to resolve the ADE diabetes problem.

These last years, the researchers developed a specific ontology for the medical errors and the Adverse Events (AEs). Stetson in 2001 [18], developed an ontology representing the intersection between medical errors, needs of information and the space of communication. The main use of this ontology is for the reasonable deployment of the computer systems . Herman et al. in 2005 [10], created an $\mathrm{AE}$ ontology for the public health vaccines, these standardized knowledge will be useful in several safety applications vaccine. Jeon and Kim in 2006 [17], developed a prototype of Ontology-based AE Reporting System (ONTERS). The main objective of this study is to facilitate sharing and exchange of $\mathrm{AE}$ information among healthcare information systems. Mokkarala et al. in 2008 [15], described the development of an ontology of medical errors to serve as a standard representation for medical errors concepts gleaned from various existing published taxonomies, with the goal of preventing errors and improving patient safety. Ceusters in 2011 [21], described an approach for the representation of AE's ontology to bring clarity to the terminology of AE. He et al. in 2011 [23], present the realism-based biomedical Ontology for Adverse Events (AEO) in the goal to reduce the confusion in $\mathrm{AE}$ terminology. The AEO provides an opportunity for the $\mathrm{AE}$ research community to work together towards realism-based $\mathrm{AE}$ information representation and data analysis. Jaya in 2011 [2], discusses the construction of ontology of diabetes's symptoms. This work aims to diagnose and predict the diabetes in the earlier stage and helps to provide the possible meaningful factors which leads to diabetes. Cantais et al. in 2005 [11], present a food ontology for diabetes. They aim to represent an abstract model of the different types of foods, with their nutritional information, including the type and amount of nutrients, and the recommended daily intake to help the diabetic patients.

Now days, several AE representation systems have been proposed thus far while others are under development. For exemple, Ontology-based Adverse Event Reporting System (ONTERS), Adverse Events Ontology (AEO), International Classification Disease (ICD), Symptoms ontology for diabetes, Food Ontology Diabete,... (see Table 1).

Our work aims to construct a knowledge background for computer systems to prevent the diabetes ADE, by the construct of ontology diabetes ADE. This ontology regroupes and structures the information about the ADE of diabetes disease. It aimes to represent diabetes ADE knowledge in the purpose of facilitating the extraction of the information used in the analysis and improving the diabetes ADE prevention and the detection of diabetes ADE.
Table 1: Summary of medical ontologies

\begin{tabular}{|c|c|c|}
\hline Source & Ontology & Issue \\
\hline $\begin{array}{c}\text { Who } 1993 \\
\text { [22] }\end{array}$ & $\begin{array}{l}\text { International } \\
\text { Classification } \\
\text { Disease (ICD) }\end{array}$ & $\begin{array}{l}\text { Classifing disease, } \\
\text { conditions, symp- } \\
\text { toms, injury... }\end{array}$ \\
\hline $\begin{array}{l}\text { Price et al. } \\
2000[16]\end{array}$ & $\begin{array}{c}\text { Systematized } \\
\text { Nomenclature of } \\
\text { Medicine } \\
\text { (SNOMED) }\end{array}$ & $\begin{array}{l}\text { Making medical } \\
\text { knowledge accessible } \\
\text { by all medical } \\
\text { community. }\end{array}$ \\
\hline $\begin{array}{l}\text { Herman et } \\
\text { al. } 2005 \\
{[10]}\end{array}$ & $\begin{array}{l}\text { Ontology } \mathrm{AE} \text { of } \\
\text { vaccines }\end{array}$ & $\begin{array}{c}\text { Standardizing } \\
\text { knowledge vaccines } \\
\text { for using in safety } \\
\text { application. }\end{array}$ \\
\hline $\begin{array}{l}\text { Cantais et } \\
\text { al. 2005 } \\
\text { [11] }\end{array}$ & $\begin{array}{c}\text { Food ontology for } \\
\text { diabetes }\end{array}$ & $\begin{array}{c}\text { Provision of } \\
\text { nutritional advice to } \\
\text { diabetic patient. }\end{array}$ \\
\hline $\begin{array}{l}\text { Verbeke et } \\
\text { al. 2006 } \\
{[20]}\end{array}$ & $\begin{array}{c}\text { International } \\
\text { Classification of } \\
\text { Primary Care } \\
\text { (ICPC) }\end{array}$ & $\begin{array}{l}\text { Classifing the medical } \\
\text { concepts relative to } \\
\text { primary health care }\end{array}$ \\
\hline $\begin{array}{l}\text { Jeon et al. } \\
2006 \text { [17] }\end{array}$ & $\begin{array}{l}\text { Ontology-based } \\
\text { Adverse Event } \\
\text { Reporting System } \\
\text { (ONTERS) }\end{array}$ & $\begin{array}{c}\text { Facilating AE } \\
\text { information sharing } \\
\text { and } \\
\text { exchanging among } \\
\text { healthcare } \\
\text { information systems. }\end{array}$ \\
\hline $\begin{array}{c}\text { Mokkarala } \\
\text { et al. 2008 } \\
{[15]}\end{array}$ & $\begin{array}{l}\text { Ontology of } \\
\text { medical error }\end{array}$ & $\begin{array}{l}\text { Preventing errors and } \\
\text { improving pa- } \\
\text { tient safety. }\end{array}$ \\
\hline $\begin{array}{l}\text { Ceusters et } \\
\text { al. } 2008 \\
{[21]}\end{array}$ & $\begin{array}{l}\text { Adverse Event } \\
\text { ontology }\end{array}$ & $\begin{array}{c}\text { Clarifing the } \\
\text { terminology of } \mathrm{AE} .\end{array}$ \\
\hline $\begin{array}{l}\text { He et al. } \\
2011[23]\end{array}$ & $\begin{array}{l}\text { Ontology of } \\
\text { Adverse Event } \\
\text { (AEO) }\end{array}$ & $\begin{array}{l}\text { Reducing Confusion } \\
\text { in AE terminology }\end{array}$ \\
\hline $\begin{array}{c}\text { Jaya } 2011 \\
{[2]}\end{array}$ & $\begin{array}{c}\text { Ontology of } \\
\text { diabetes's symptoms }\end{array}$ & $\begin{array}{l}\text { Predicting diabetes in } \\
\text { the earlier stage. }\end{array}$ \\
\hline
\end{tabular}

\section{ONTOLOGY OF DIABETES'ADE}

The purpose of any health institution is to increase the health quality and to decrease the medical errors frequency. The ADEs represent an important cause of morbidity even of mortality. The protection of patients from ADEs becomes a major priority of the sanitary authorities. In fact, every stage of patient's care engenders certain potential errors and risks on the patients'safety. Hence, the prevention of the ADEs presents a big challenge in the health field mainly if it is related to diabetes disease. Diabetes is sensitive to many type of ADEs because it reaches many organs and causes further diseases. For the improvement of diabetes ADE prevention and detection systems, it is necessary to improve the quality of available information. Our approach is to build a specific ontology for the diabetes'ADEs, this ontology allows to present the necessary knowledge which guarantees the coherence of axioms and integrity of the medical computer system. According to Gruber in 1993 [8], "an ontology is an explicit specification of a conceptualization". In 1998 Studer [19] defines the ontology "as a formal and explicit specification of a shared conceptualization".

So ontology is a formal representation, composed of characterizeding domain concepts shared between various users. It supplies the means to express these concepts by organizing them hierarchically and by defining their semantic properties in a formal language of knowledge 
representation [4]. The diabetes ADEs ontology presents a formal system. The objective of this ontology is to represent diabetes $\mathrm{ADE}$ knowledge and to facilitate its extraction. The development of such ontological resources will allow to finalize successful, fiables and maintenables tools to code and to improve diabetes ADEs prevention system. The reasons for constructing such ontology are [6]:

- To structure and organize diabetes ADEs domain which characterized by a very important volume of data.

- To share common understanding structure of information among people or software.

- To separate domain knowledge from the operational knowledge.

- To facilitate the extraction of the diabetes ADE knowledge of diabete from an organized source which can facilate the analysis of the knowledge.

\section{CONSTRUCTION OF DIABETES ADE ONTOLOGY}

We describe here the process for our ontology construction. The construction of ontology adapts four phases (see Figure 1):

- Phase 1: Specifing Information.

- Phase 2: Conceptualization.

- Phase 3: Formalization.

- Phase 4: Implementation.

- Phase 5: Evaluation.

\subsection{Phase 1: Specifing Information}

The main objective of this phase is to identify the need and purpose for ontology construction. This phase consists in establishing an informal document to describe the diabetes ADE ontology and acquire the knowledge about the diabetes and $\mathrm{ADE}$ domain in order to analyze the necessary requirements. It also identifies the range of the users and the type of questions which the ontology should answer. The knowledge for ontology can be acquired from, books, research papers, experts, patients, encyclopedias... (see Table 2).

\section{Table 2: Specifing information of diabetes ADE} ontology

\begin{tabular}{|c|c|}
\hline Domain & Medical ontology specific on ADE diabetes \\
\hline Objectif & $\begin{array}{c}\text { The ADE diabetes ontology presents a formal } \\
\text { representation which aimed to represent the } \\
\text { knowledge of ADE relative to diabetes disease. } \\
\text { This ontology provides methodological help by } \\
\text { capitalizing knowledge and facilating its } \\
\text { extraction. The development of such } \\
\text { ontological resources can improve the systems } \\
\text { to prevent diabetes ADE }\end{array}$ \\
\hline User & $\begin{array}{c}\text { Software Developer, health professionals, } \\
\text { endocrinologists ... }\end{array}$ \\
\hline $\begin{array}{c}\text { Informati } \\
\text { on } \\
\text { source }\end{array}$ & $\begin{array}{c}\text { Medical encyclopedia, technical document } \\
\text { related to diabetes (book, article ...), technical } \\
\text { document related to the ADE, experts... }\end{array}$ \\
\hline
\end{tabular}

\subsection{Phase 2: Conceptualization}

This phase consists on organizing and structuring, the information sources of the domain by using an intermediate formal representation, for exemple tables and graphs. At the end we obtain an abstract ontology (abstract model). We present in follows an example of some stages of conceptualization of ontology.

- Presentation of concepts glossary, it groups and describes in natural language all the useful concepts in the field of the diabetes ADEs.

- Definition of the classes and class hierarchy used to identify terms, the concepts are modeled as classes or sub classes.

- The relationships between the concepts, for every relationship we specify the source concept, the target concept and the cardinality.

- The properties of classes, it consist of specifing the properties describing every concept.

- Definition of the instance of classes, which indicates the concrete example of concepts within the domain.

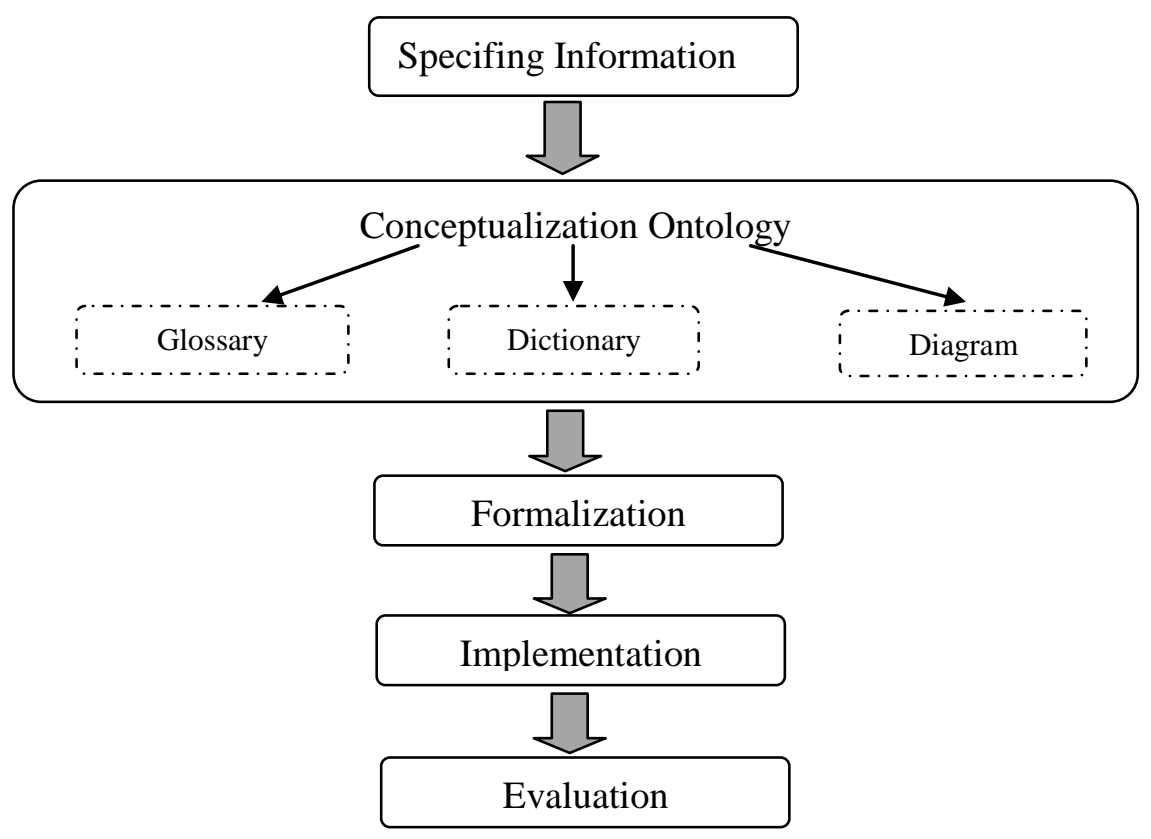

Fig 1: The process of the ontology construction 
These stages identify the key concepts of the diabetes ADE domain, their properties and the relationships that hold between them. Figure 2 presents the concepts of $\mathrm{ADE}$ diabetes and the relationship between them (see Figure 2).

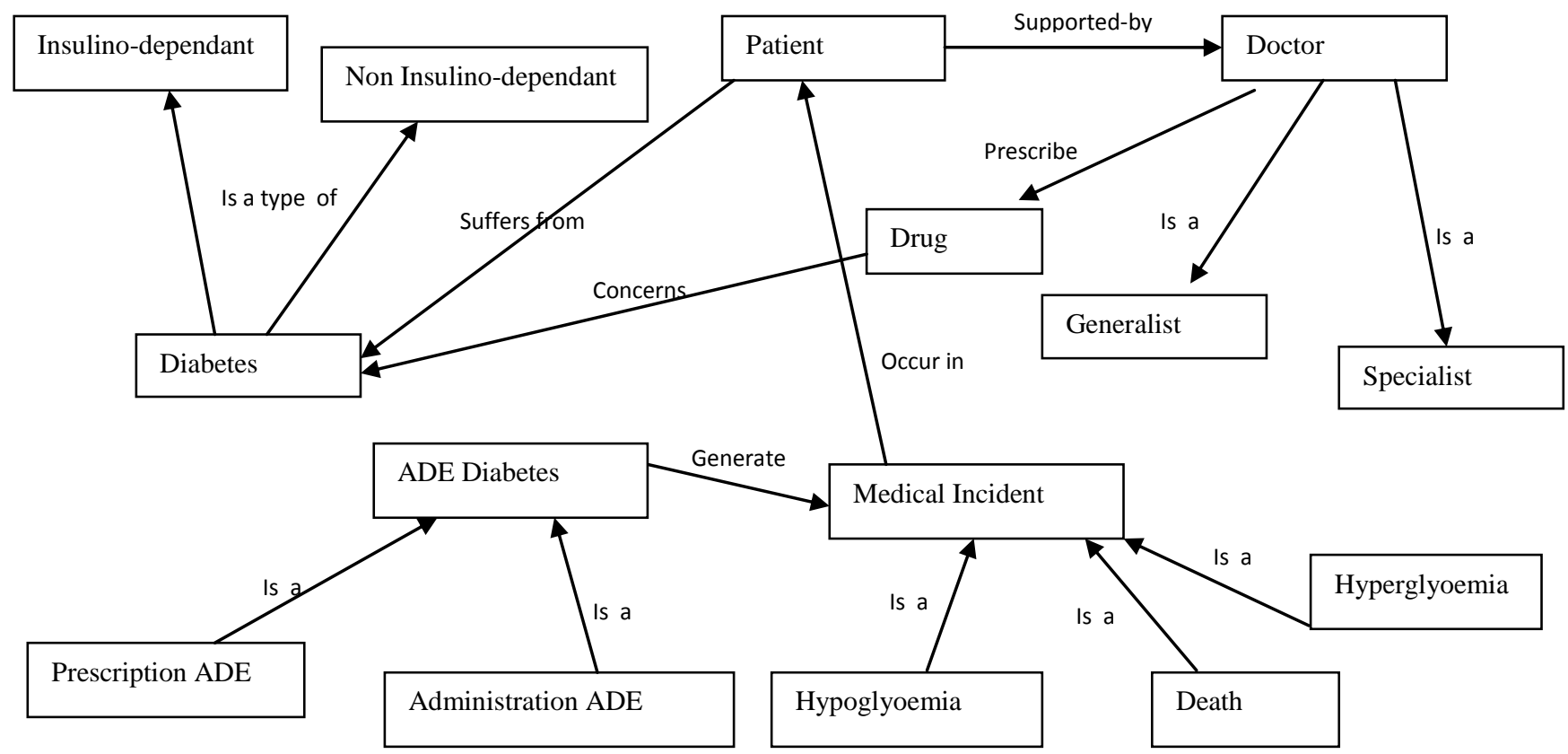

Fig 2: Diagram of the relationship between concepts of diabetes ADE ontology

\subsection{Phase 3: Formalization}

It consists on formalizing the abstract ontology obtained in the previous phase to a formal and operational language. We use for the formalization a knowledge representation language (so called logic) which can be used to represent the terminological domain knowledge in a formal and structured way. For exemple logic FL-, logic AL, logic SHOIN...etc. The result of this phase is a formal ontology (formal model). The logic used in this paper is logic SHOIN which is a very expressive description logic and it has a clear semantics (see Figure 3).

\section{Axioms used to describe classes of the ontology of ADE diabetes}

Patient $\subseteq \mathrm{T} \cap(\square \exists$ Number_of_national_identity_card.String $) \cap(\square \exists$ Name.String $) \cap(\square \exists$ First_name.String $) \cap$ ( $\exists$ Date_of_birth.String) $\cap$ $(\exists$ Adress.String $) \cap(\exists$ Social_securite_number.String $) \cap(\exists$ Phone.String $) \cap(\exists$ Email.String $) \cap(\exists$ Profession.String $) \cap(\square$

$\exists$ Family_situation.String $) \cap(>=1$ Suffer_from $)$

Doctor $\subseteq \mathrm{T} \cap(\square \exists$ Number_of_national_identity_card..String $) \cap(\square \exists$ Name.String) $\cap(\square \exists$ First_name.String) $\cap$ ( $\exists$ Date_of_birth.String) $\cap(\exists$ Adress.String $) \cap(\exists$ Social_securite_number.String $) \cap(\exists$ Phone.String $) \cap(\exists$ Email.String $) \cap(\exists$ Profession.String $) \cap($ $\exists$ Speciality.String $) \cap(\square \exists$ Family_situation.String $) \cap(>=1$ Prescribe $)$

Drug $\subseteq \mathrm{T} \cap$ ( $\square \exists$ Drug_name.String) $\cap(\square \exists$ Drug_Component.String) $\cap$ (=1Concern)

Medical_Incident $\subseteq \mathrm{T} \cap(\square \exists$ Date_begin_incident.String $) \cap(\square \exists$ Date_end_incident.String $) \cap(\square \exists$ Period_incident.String $) \cap(>=0$ Occur_in)

ADE_diabetes $\subseteq T \cap(\square \exists$ Date_ADE_diabetes.String $) \cap(>=1$ Engender $)$

Incident_Death $\subseteq$ Medical_Incident

\section{Axiomes are used to describe the relationships between classes}

Incident_Hyperglycemia $\subseteq$ Medical_Incident

Incident_Hypoglycemia $\subseteq$ Medical_Incident

Generalist_Doctor $\subseteq$ Doctor

Specialist_Doctor $\subseteq$ Doctor

ADE_diabetes $\cap$ Diabetes $\cap$ Drug $\cap$ Doctor $\cap$ Patient $\subseteq \perp$

Generalist_Doctor $\cap$ Specialist_Doctor $\subseteq \perp$

Incident_Death $\cap$ Hypoglycemia_Incident $\cap$ Hyperglycemia_Incident $\subseteq \perp$

Insulino_dependant_diabetes $\cap$ Non_Insulino_dependant_diabetes $\subseteq \perp$

Administration_ADE $\cap$ Prescription_ADE $\subseteq \perp$ 


\subsection{Phase 4: Implementation}

The purpose of this phase consists on encoding the formal ontology on an ontology implementation language to make it operational. It's realized by using a tool of ontologies edition. The source ontologies were implemented using the Protégé tool which is an ontology editor that provides a graphical representation of the ontology and generates the code OWL (Ontology Web Language) which can be used in ADE prevention on systems programming [7]. There are many steps to create the ontology using Protégé tool.
1- The first step is to create the hierarchy of the ontology's concepts and their definition. The hierarchy is composed of classes (Patient, drug, doctor...) and of sub-classes (medical incident, death, hyperglycemia, hypoglycemia, insulino-dependant, ...) (see Figure 4).

2- The second step consists on presenting the relationship between the concepts and its characteristics.

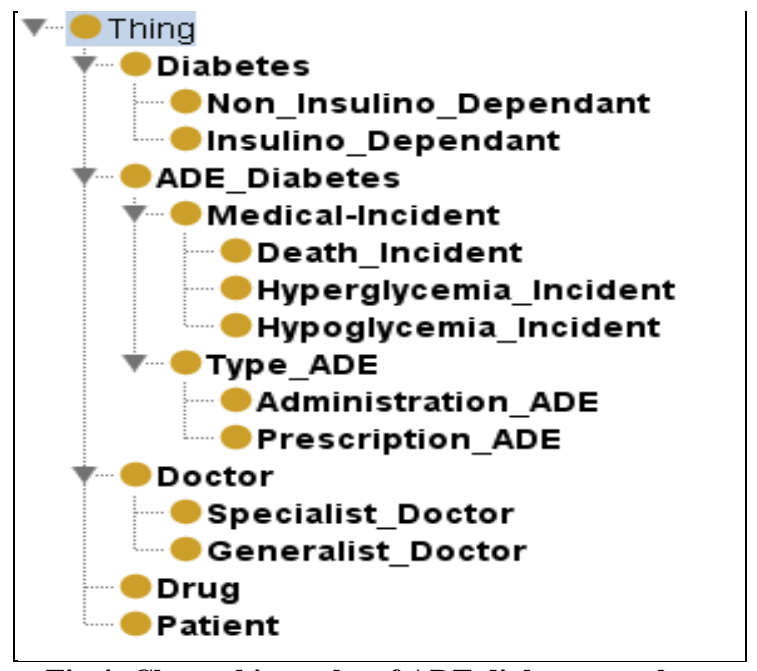

Fig 4: Classes hierarchy of ADE diabetes ontology

3- The third step consists on associating for every concept its properties. These properties correspond to the attribute of every class. Every class has a specific attribute which distinguishes it from the others, so they allow to connect the classes (see Figure 5).

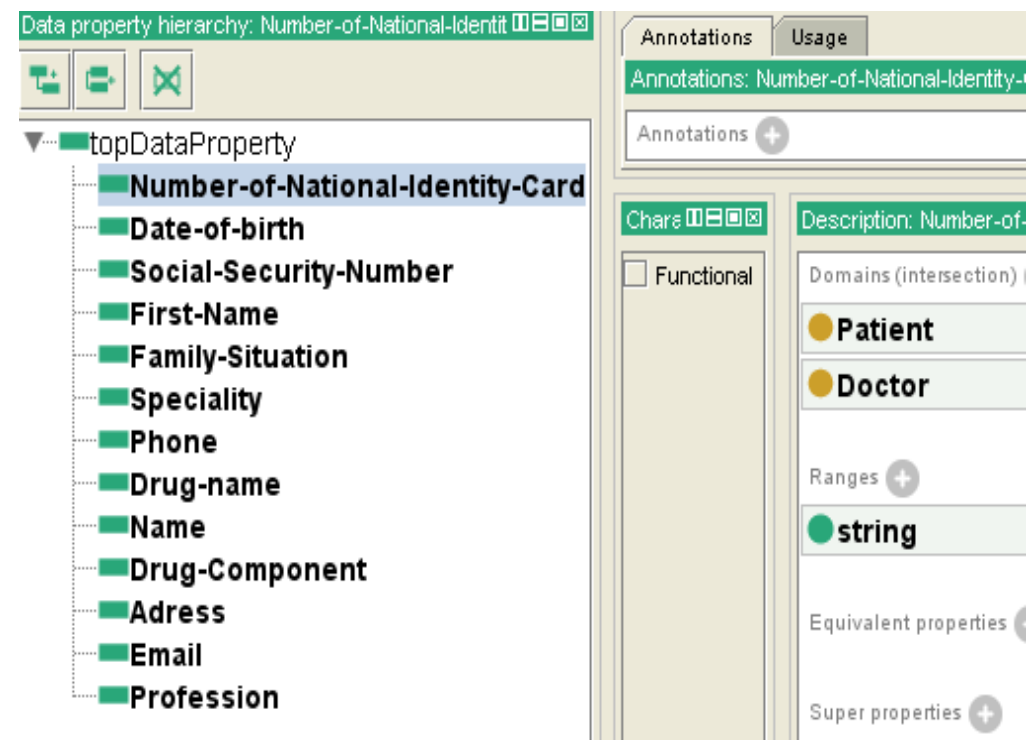

Fig 5: The propriety of classes's ontology

4- The fourth step consists on adding the instance for every class if it is necessary. For exemple Insuline,

Glycose for drug's class (see Figure 6). 


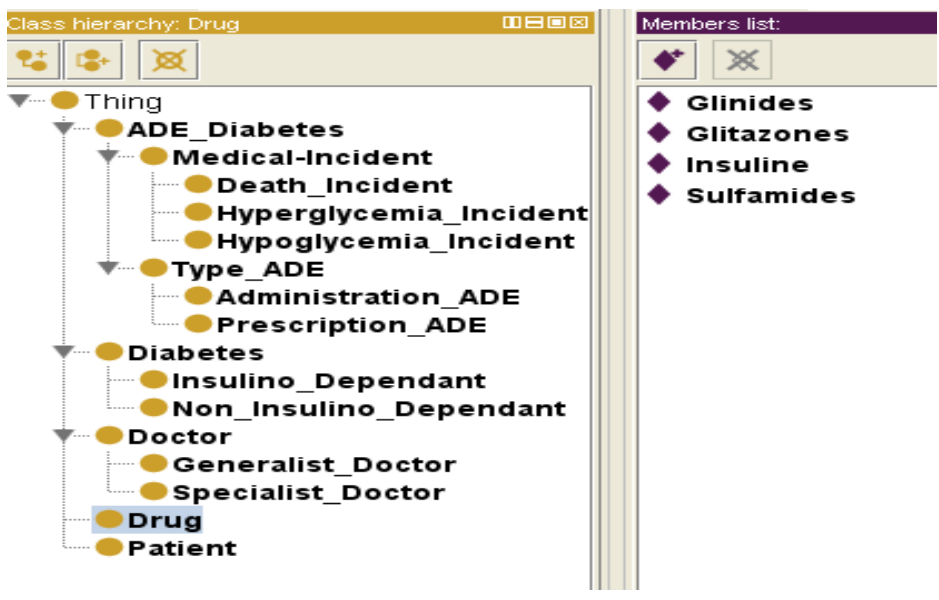

Fig 6: Instance of drug's class

\subsection{Phase 5: Evaluation}

This step consists on evaluating and updating of our ontology. This step of evaluation can be made in parallel with the previous three steps. It is made at the abstract level, at the formal and operational level. Diabetes ADE ontology is used in medication process in order to prevent the ADE diabetes. It helps for reasoning the cases semantically.

\section{CONCLUSION}

The purpose of ADE diabetes ontology is to improve safety of diabetic patients by reducing the medical errors relative to drug administration. In this paper, we developed an diabetes ADEs ontology which groups the terms relative to $\mathrm{ADE}$ and diabetes disease in a formal way. This ontology is a formal representation, defining in a given language the relationships which they maintain between them. This ontology is a background knowledge wihch serves to limit the domain of the $\mathrm{ADE}$ diabetes, and to facilitate the extraction of the knowledge. Also, it can be used to develop a preventive ADE system to increase the health quality and decrease unnecessary expensens.

\section{ACKNOWLEDGMENTS}

We would like to thank Mrs. Nouira Kaouther for her direction, recommendations and suggestions.

\section{REFERENCES}

[1] Jamoussi, S., Kammoun, H., Souissi, S., Nagati, K., Abid, A., Chabchoub, S. 2000. Direct cost of diabetes in tunisia. Diabetes Research and Clinical Practice. Volume 50 (1), 191.

[2] Jaya, A. 2011. A standard methodology for the construction of symptoms ontology for diabetes diagnosis. International Journal of Computer Applications. Volume 14(1)( January 2011), 47-51.

[3] American Diabetes Association. Economic costs of diabetes in the u.s. in 2007. Diabetes Care, 2008.

[4] Bourigault, D., Aussenac-Gilles, N., Charlet, J. 2004. Construction de ressources terminologiques ou ontologiques a partir de textes : un cadre unificateur pour trois études de cas. Revue d'Intelligence Artificielle. Volume 18(1), 87-110.
[5] Ehsani, J.P., Jackson, T., Duckett, S.J. 2006. The incidence and cost of adverse events in victorian hospitals. Med J Aust. Volume 184(11) (June 2006), 551-555.

[6] Florea, A., Caughey, S.S., Westland, J., Berckmans, M., Kennelly, C., Beach, C., Dyer, A., Forster, A.J., Oppenheimer, L.W. 2010. The ottawa hospital quality incident notification system for capturing adverse events in obstetrics. J Obstet Gynaecol Can. Volume 32(7) (July 2010), 657-62.

[7] FridmanNoy, R., Fergerson, W., Musen, A.M. 2000. The knowledge model of protg-2000: combining interoperability and exibility. Lecture Notes in Computer Science. Volume 1937 (2000), p. 69-82.

[8] Gruber, T.R. 1993. A translation approach to portable ontologies specification. Knowledge Acquisition. Volume 5 (2) (June 1993), 199-220.

[9] Handler, S.M., Altman, R.L., Perera, S., Hanlon, J.T., Studenski, S.A., Bost, J.E., Saul, M.I., Fridsma, D.B. 2007. A systematic review of the performance characteristics of clinical event monitor signals used to detect adverse drug events in the hospital setting. Journal of the American Medical Informatics Association. Volume 14(4) (July 2007), 451-158.

[10] Sagaram, D., Kamadjeu, R., Fontelo, P., Kohl, K., Payne, D., Tolentino, H.D., Liu, F. 2005. Creating a vaccine adverse event ontology for public health. AMIA. (2005), 978.

[11] Cantais, J., Gigante, V., Dominguez, D. 2005. An example of food ontology for diabetes control. Proceedings of the International Semantic Web Conference 2005 workshop on Ontology Patterns for the Semantic Web.

[12] Kohn, L.T., Corrigan, J., Donaldson, M.S. 2000. To err is human: building a safer health system. National Academy Press, Washington. Volume 21(6), 453-454.

[13] Nebeker, J.R., Barach, P., Samore, M.H . 2004. Clarifying adverse drug events: A clinician's guide to terminology, documentation, and reporting. Ann Intern Med. Volume 140(10), 795-801.

[14] Burgun, A., Bodenreider, O., Smith, B. 2004. The ontology-epistemology divide: A case study in medical terminology. Proceedings of the Third International Conference on Formal Ontology in Information Systems (FOIS 2004). 185-195. 
[15] Mokkarala, P., Johnson, T.R., Patel, V.L., Zhang, J., Turley, J.P., Brixey, J. 2008. Development of a comprehensive medical error ontology. Advances in Patient Safety: New Directions and Alternative Approaches. Volumes 1-4 (July 2008).

[16] Stearns, M.Q., Price, C., Spackman, K.A., Wang, A. Y. 2001. Snomed clinical terms. Proceedings of the AMIA Symposium. (2001), 662-666.

[17] Kim, H.J., Jeong, S. 2006. Ontology based adverse event reporting system architecture. World library And information congress: 72nd ifla general conference and council. Volume 12(2006), 17-20.

[18] Stetson, P.D., McKnight, L.K., Bakken, S., Curran, C. Kubose, T.T., Cimino, J.J. 2001. Development of an ontology to model medical errors, information needs, and the clinical communication space. J Am Med Inform Assoc. Volume 9(6 Suppl 1) (Nov-Dec 2002), 86-91.
[19] Studer, R., Benjamins, R.V., Fensel, D. 1998. Knowledge enginerinng: principales and methods. Data Knowl. Eng. Volume 25(1-2)(1998), 161-197.

[20] Verbeke, M., Schrans, D., Deroose, S., Maeseneer, J.D. 2006. The international classification of primary care (icpc-2):an essential tool in the epr of the gp. Stud Health Technol Inform. Volume 124 (2006), 809-814.

[21] Moor, G.D., Devlies, J., Ceusters, W., Capolupo, M. 2008. Introducing realist ontology for the representation of adverse events. Proceedings of the 2008 conference on Formal Ontology in Information Systems: Proceedings of the Fifth International Conference.

[22] Who,I. 1993. Manual of the international statistical classification of diseases, injuries and causes of death, 1993. World health organisation.

[23] Sarntivijai, S., Toldo, L., Ceusters, W., He, Y., Xiang, Z. 2011. Aeo: A realism-based biomedical ontology for the representation of adverse events. ICBO: International Conference on Biomedical Ontology. 2011. 